\title{
WIK/AB Zebrafish
}

National Cancer Institute

\section{Source}

National Cancer Institute. WIK/AB Zebrafish. NCI Thesaurus. Code C79989.

A wild-type zebrafish line. 